\title{
The Society for Computer Applications in Radiology
}

$\mathbf{T}$

HE COMING year will be as exciting and challenging for SCAR as the previous one.

At the annual meeting during Radiologic Society of North America new members were elected to the Society for Computer Applications in Radiology (SCAR). For the Executive Committee, Alan H. Rowberg, MD was elected as Chairman, Jeffrey L. Creasy, MD as ViceChairman, Melvyn Greberman, MD, MPH, as Secretary, David Beard, PhD as Treasurer, and John Boehme, MS and Heinz U. Lemke as Directors-at-Large. In continuing roles on the Committee are Carl Ravin, MD as Past Chairman, David Avrin, MD, PhD, as reduced instruction set computers Liaison, and Roger Bauman, $\mathrm{MD}$, as Editor of the Joumal of Digital Imaging.

The SCAR '92 meeting will be held June 14 to 17 and promises to be the biggest and best one yet. Baltimore has gone through a metamorphosis, and is now a wonderful city to visit, especially in June. The Inner Harbor area, near the Omni, our meeting hotel, is especially attractive for family activities. The Monday evening reception will be held at the Aquarium and should be the highlight of the meeting.

One of the most effective parts of SCAR's organizational structure has been the development of special interest groups (SIG) within the organization. The two current SIGs are concerned with radiology reporting methods, for which draft position papers have been prepared and the technology forum, which has developed a 32-page handbook entitled "Understanding PACS."

Special interest groups offer an opportunity for both the health care industry and clinical members to come together to work on projects of mutual interest. This has proven to be a good model for collaboration, and we would like to see the day when every SCAR member participates in a SIG. SCAR is interested in starting additional SIGs during the coming year, and would be receptive to suggestions from the membership.

During the past 2 years our several publications have enjoyed success and we are especially pleased that the Journal of Digital Imaging is now included in Index Medicus. Dr Roger Bauman, his editorial staff, and the contributing authors have done a remarkable job. The membership has enjoyed the SCAR News with Dr Robert Hindel as editor, and he would be delighted to receive drafts of articles and suggestions from you.

During 1992 the recruitment of new members will emphasize the eligibility of health care industry representatives as well as clinical and academic participants. Those of you who receive the journal should encourage colleagues to consider the advantages of membership in SCAR and attendance at the ' 92 conference. Application forms and advance registration materials can be obtained from the SCAR office at (717) $561-5266$ or fax to (717) $561-5360$. The address is Society for Computer Applications in Radiology, PO Box 8800, Harrisburg, PA 171058800 . We look forward to your continued participation in SCAR and seeing you and your colleagues at the SCAR meeting in Baltimore this summer.

Alan H. Rowberg, MD Chairman, SCAR Department of Radiology University of Washington Seattle, WA 98195 